\title{
Genes implicados en la gravedad de la infección por SARS-cov- 2
}

\author{
Genes involved in the severity of SARS-cov- 2 infection \\ Genes envolvidos na gravidade da infecção pelo SARS-cov- 2
}

\author{
Andrea Tenesaca Serpa \\ andrea.tenesaca@ucacue.edu.ec \\ https://orcid.org/0000-0002-7300-821X
}

\author{
Diego Andrade Campoverde \\ dandrade@ucacue.edu.ec \\ https://orcid.org/0000-0003-4652-7708
}

\section{Programa de Maestría en Diagnóstico de Laboratorio Clínico y Molecular Universidad Católica de Cuenca, Cuenca-Ecuador}

Recibido 2 de marzo 2021 | Arbitrado y aceptado 26 de marzo 2021 | Publicado en 4 de mayo 2021

\begin{abstract}
RESUMEN
El COVID-19 es una patología producida por el SARS-CoV-2, virus de carácter zoonótico capaz de producir patologías multiorgánicas. La sintomatología que produce es variada. Ante la infección algunos pacientes presentan condiciones de gravedad. Los estudios han demostrado que el rol genético tiene gran afluencia sobre la respuesta ante la infección. El objetivo de investigación es detallar los genes que están implicados en la gravedad de la infección por SARS-CoV- 2. Metodología. Se realizó una revisión sistemática, con base a la búsqueda y análisis de artículos originales en bases de datos de alto impacto como PudMed, Google Académico, Scopus, Taylor \& Francis, ProQuest SciencieDirect; se utilizaron operadores booleanos, criterios de inclusión y exclusión con el objetivo de obtener información precisa. Los genes de inmunidad como el HLA, ACE2 y TMPRSS2 están directamente involucrados con la gravedad de la infección por SARS-CoV- 2. Los polimorfismos de los genes del polyQ del receptor de andrógenos, factor $\mathrm{ABO}$ coadyuvan a un deterioro del estado patológico como consecuencia de la COVID-19. Conclusión. Los estudios demostraron que existen genes involucrados en la gravedad ante la infección de SARS -CoV-2, pues mencionan que los polimorfismos de los genes; HLA, del polyQ del receptor de andrógenos y factor ABO producen susceptibilidad ante el COVID-19. Así mismo los genes ACE2 y TMPRSS2 intervienen en el ingreso y expansión del virus. En las diversas razas existen variantes de los genes CCL2 y MBL lo que indica que algunas poblaciones son más susceptibles que otras.
\end{abstract}

Palabras clave: COVID-19; SARS-CoV- 2; HLA, TMPRSS2, CCL2, MBL, IL6, polimorfismo, poliglutamina, patogénesis, inmunidad, susceptibilidad, factor $\mathrm{ABO}$

\begin{abstract}
COVID-19 is a pathology caused by SARS-CoV-2, a zoonotic virus capable of producing multi-organ pathologies. The symptomatology it produces is varied. Some patients present severe conditions after infection. Studies have shown that the genetic role has a great influence on the response to infection. Methodology. A systematic review was carried out, based on the search and analysis of original articles in high impact databases such as PudMed, Google Scholar, Scopus, Taylor \& Francis, ProQuest SciencieDirect; Boolean operators, inclusion and exclusion criteria were used in order to obtain accurate information. Immunity genes such as HLA, ACE2 and TMPRSS2 are directly involved with the severity of SARS-CoV- 2 infection. Polymorphisms of androgen receptor polyQ genes, $\mathrm{ABO}$ factor contribute to a deterioration of the pathological state as a consequence of COVID-19. Conclusion. The studies demonstrated that there are genes involved in the severity of SARS-CoV-2 infection, since they mention that polymorphisms of the HLA, androgen receptor polyQ and $\mathrm{ABO}$ factor genes produce susceptibility to COVID-19. Likewise, ACE2 and TMPRSS2 genes intervene in the entry and expansion of the virus. In the different breeds there are variants of the CCL2 and MBL genes, which indicates that some populations are more susceptible than others.
\end{abstract}

Key words: COVID-19; SARS-CoV- 2; HLA; TMPRSS2; CCL2; MBL; IL6; polymorphism; polyglutamine; pathogenesis; immunity, susceptibility, ABO factor

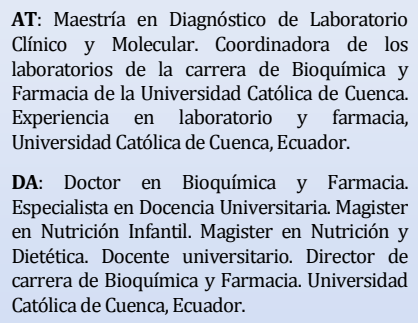
AT: Maestría en Diagnóstico de Laboratorio
Clínico y Molecular. Coordinadora de los Clínico y Molecular. Coordinadora de los
laboratorios de la carrera de Bioquímica y laboratorios de la carrera de Bioquímica y
Farmacia de la Universidad Católica de Cuenca. Farmacia de la Universidad Católica de Cuenca. Experiencia en laboratorio y farmat
Universidad Católica de Cuenca, Ecuador. DA: Doctor en Bioquímica y Farmacia. Especialista en Docencia Universitaria. Magister en Nutrición Infantil. Magister en Nutrición y Dietética. Docente universitario. Director de carrera de Bioquímica y Farmacia. Universidad Católica de Cuenca, Ecuador. 
AT: Maestría en Diagnóstico de Laboratorio Clínico y Molecular. Coordinadora de los laboratorios de la carrera de Bioquímica y Farmacia de la Universidad Católica de Cuenca. Experiencia en laboratorio y formacia Experiencia en laboratorio y farmacia

DA: Doctor en Bioquímica y Farmacia Especialista en Docencia Universitaria. Magister en Nutrición Infantil. Magister en Nutrición y en Nutricón lnfanti. Magister en Nutrición y Dietética. Docente universitario. Director de acia. Universidad Católica de Cuenca, Ecuador.

\section{RESUMO}

COVID-19 é uma patologia causada pelo SARS-CoV-2, um vírus zoonótico capaz de produzir patologias multiorganismos. Os sintomas que ela produz são variados. Alguns pacientes se apresentam com condições severas após a infecção. Estudos demonstraram que o papel da genética desempenha um papel importante na resposta à infecção. 0 objetivo desta pesquisa é detalhar os genes que estão envolvidos na gravidade da infecção pelo SARS-CoV- 2. Metodologia. Foi realizada uma revisão sistemática, baseada na busca e análise de artigos originais em bancos de dados de alto impacto como PudMed, Google Scholar, Scopus, Taylor \& Francis, ProQuest SciencieDirect; operadores booleanos, critérios de inclusão e exclusão foram utilizados para obter informações precisas. Resultados. Os genes de imunidade como HLA, ACE2 e TMPRSS2 estão diretamente envolvidos na gravidade da infecção pelo SARS-CoV- 2. Os polimorfismos dos genes receptores de androgênio polyQ, fator $\mathrm{ABO}$ contribuem para uma deterioração do estado patológico como conseqüência da COVID-19. Conclusão. Os estudos demonstraram que existem genes envolvidos na gravidade da infecção pelo SRA-CoV-2, pois mencionam que os polimorfismos dos genes HLA, androgênio receptor policarbonato e fator $\mathrm{ABO}$ produzem suscetibilidade à COVID-19. Os genes ACE2 e TMPRSS2 também estão envolvidos na entrada e propagação do vírus. Existem variantes dos genes CCL2 e MBL nas diferentes raças, indicando que algumas populações são mais suscetíveis do que outras.

Palavras-chave: COVID-19; SARS-CoV- 2; HLA, TMPRSS2, CCL2, MBL, IL6, polimorfismo, poliglutamina, patogênese, imunidade, suscetibilidade, fator $\mathrm{ABO}$

\section{INTRODUCCIÓN}

A finales del año 2019 se desencadenó un rotundo cambio de convivencia en todo el mundo, pues inició una de las más grandes pandemias de siglo XXI. Los estudios manifiestan que el origen de la pandemia se suscitó en China tras reportarse 27 casos de pacientes con neumonía no conocida (1), en las radiografías de tórax (2), encontraron cambios a nivel pulmonar como tromboembolismo (3) así como también síntomas multiorgánicos (4).

A principios de enero del 2020 varios países manifestaron alrededor de 2000 casos de pacientes con neumonía, síndromes respiratorios y síntomas similares a los pacientes que se reportaron en China (5), incrementándose esta cifra a 7818 pacientes a finales del mismo mes (6).

El 12 de enero del 2020 científicos chinos identificaron al virus (7) "SARS-CoV2 ", el cual pertenece a la familia de los coronavirus con características similares al virus del SARS por la producción de un síndrome respiratorio (7).

En un comienzo se creía que el virus mayormente afectaba a personas vulnerables a ancianos y a la población que tenían una edad comprendida entre los 40 a 55 años (8). Sin embargo, hasta el momento existen 167.951.168 personas con COVID-19 en todo el mundo y 3.488 .242 muertes ocasionadas por el virus (8).

Los investigadores confirmaron la aparición de nuevos síntomas y afecciones provocados por el "SARS-CoV-2, Dawei Wang y colaboradores comunicaron por medio de su estudio que pacientes exhibieron; tos seca, fatiga, fiebre, diarrea, linfopenia, alteraciones en el tiempo de protrombina, elevado nivel de lactato y el síndrome respiratorio, mientras otros no presentaron síntomas (9). De la misma manera otros casos clínicos reportaron afecciones graves como daños renales, hepáticos, problemas cardíacos e 
incluso manifestaron muertes ocasionadas por el virus (10).

Hasta el momento se conoce que el grado de afección del virus es variable, de hecho investigaciones han manifestado que los genes, las variaciones o los polimorfismos de los mismos son bases fundamentales para tratar de comprender el comportamiento del virus en los humanos (11).

Benetti y colaboradores, comunicaron a través de su investigación realizada en la población Italiana la importancia de las variabilidades de las posiciones del gen ACE2 ya que el cambio de las mismas pueden indicar susceptibilidad ante el virus por ello manifestaron que de 7000 exomas que obtuvieron para su estudio se observaron alteraciones en las posiciones "p.Asn720Asp, p.Lys26Arg, p.Gly211Arg”, demostrando que la población estudiada en comparación con la población de Asia presentaban susceptibilidad ante el virus por dichas variaciones (12).

Otro estudio demostró que al existir variaciones del gen "TMPRSS2" y "mayor actividad enzimática del mismo" la población puede presentar una mayor pre disponibilidad ante la afección del virus trayendo peligrosas consecuencias clínicas (13).

También, mencionaron que el gen "APOE (denominado e4e4)" está presente en personas con Alzheimer y en algunos grupos poblacionales, por ello al poseer el gen mencionado existe un mayor riesgo de contagio de SARS-CoV-2 (14).

De igual manera, hay investigaciones que manifiestan que los polimorfismo de los genes del HLA están relacionados con el grado de susceptibilidad al ingreso del virus (15).

En el poco tiempo de estudio del virus no se ha obtenido datos concretos que permitan correlacionar a los genes y la susceptibilidad de los organismos frente a la infección por
SARS-CoV-2. Por tanto, esta investigación busca recolectar la mayor evidencia posible para contestar la siguiente pregunta ¿Qué genes podrían estar implicados en la gravedad de la infección por SARS-CoV-2?

\section{METODOLOGÍA}

$\mathrm{S}$ e ejecutó una revisión sistemática con base en análisis de artículos originales encontrados en bases de datos publicados desde diciembre del 2019 inicio del 2021, que aportaban información sobre los genes que pueden tener relación con agravar los procesos de infección por SARS-CoV-2. También se utilizaron artículos originales desde el año 2010 que aportan con la descripción y replicación de la familia Coronaviridae y artículos originales desde el año 2002 que permitieron explicar los mecanismos, origen y funciones de las citoquinas.

Para el proceso de revisión fueron consideradas y consultadas bases de datos e indizadores como PudMed, Google Académico, Scopus, Taylor \& Francis, ProQuest y SciencieDirect en donde se analizaron artículos originales, además se consultó en las revistas científicas Lancet y Jama.

Para una búsqueda específica se utilizaron operadores booleanos, palabras clave incluidas en el tesauro DeCs, o de sus equivalentes en inglés contenidos en el tesauro MeSH, Genes y suceptibilidad (genes and susceptibility), genes de inmunidad y coronavirus (coronavirus and immunity genes), COVID-19 y características clínicas (COVID-19 and clinical features), COVID-19 y gravedades clínicas (COVID-19 and clinical severity),variaciones del gen TMPRSS2 (variations of the "TMPRSS2" gene), variaciones del gen ACE II y COVID-19 
(ACE II and COVID-19 gene variations), polimorfismos de la IL-6 (IL-6 polymorphisms), genes del grupo sanguíneo $\mathrm{AB}(\mathrm{AB}$ blood group genes and COVID-19). La búsqueda se ejecutó en las referencias bibliográficas de los artículos analizados, así como también en la página de la OMS.

Criterios de inclusión: artículos originales de fuentes primarias que contengan información relacionada a los genes implicados en la gravedad de una infección por SARS-CoV-2.

Criterios de exclusión: se excluyeron artículos que no estaban indexados en revistas de alto impacto que contenían información imprecisa y artículos originales en cuyas investigaciones no se consideraban temas sobre genes implicados en la gravedad de una infección por SARS-CoV-2.
Por consiguiente, se presenta un diagrama en el que se explica el proceso de selección de la información.

Se registraron 300 artículos en las distintas bases científicas, 150 artículos fueron eliminados tras verificar que se encontraban duplicados. Posteriormente se analizaron 40 artículos y se excluyeron 24 por no poseer información relacionada con los genes implicados en la gravedad por SARS-CoV2. Ocasionalmente 16 artículos cumplieron con los criterios de inclusión. Ver Figura 1. 


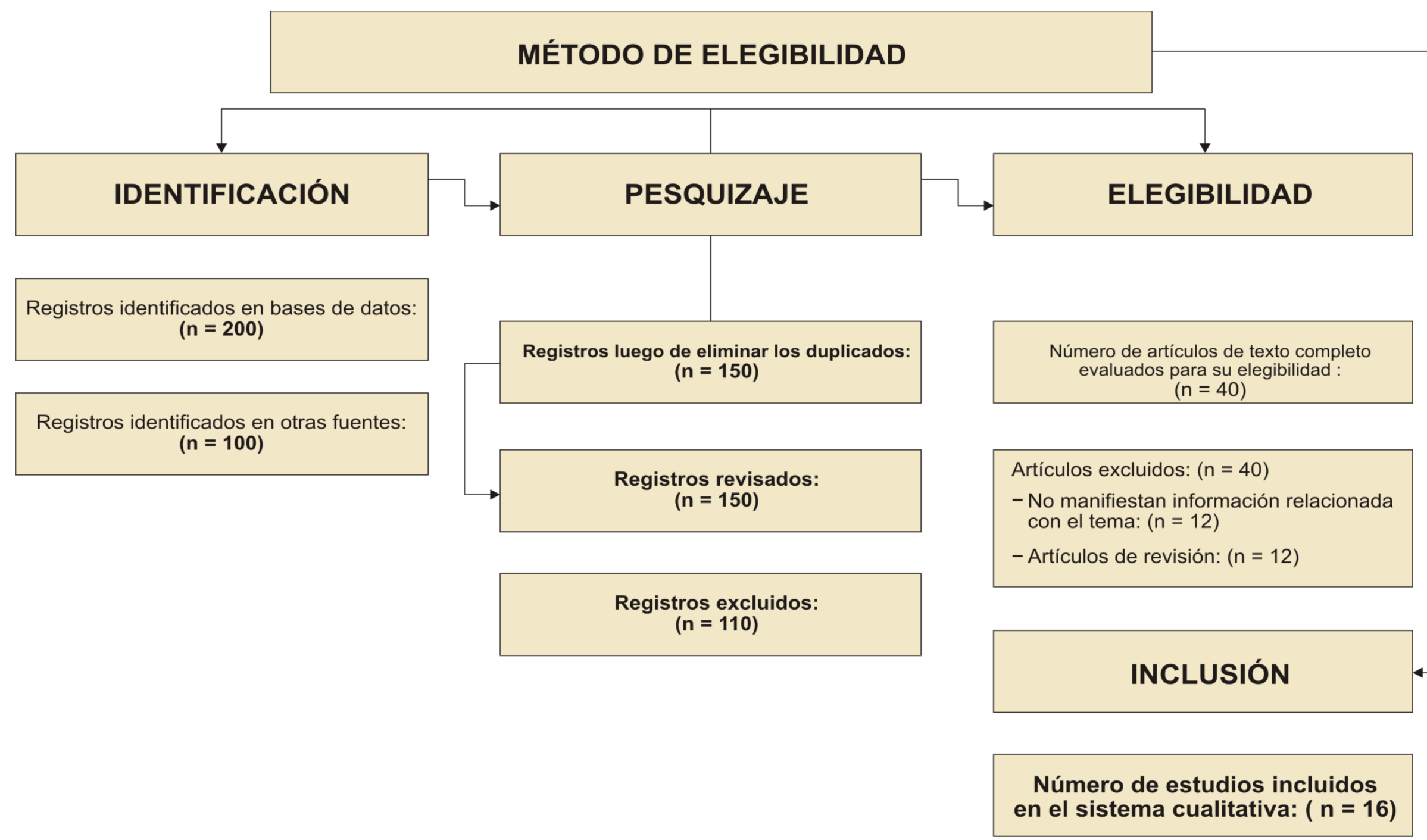

Figura 1. Diagrama de flujo elegibilidad de los artículos 


\section{DESARROLLO Y DISCUSIÓN}

$\mathrm{E}$ $n$ el siguiente apartado se muestra en la Tabla 1, la clasificación de los artículos analizados según la base de datos o plataforma consultada, el año de la publicación, el nombre de la revista, el título del artículo, los autores de los citados manuscritos y el país al cual pertenecen. Seguidamente se muestra un análisis de acuerdo a las variables mencionadas en el método sobre la enfermedad SARS-CoV - 2 .

Tabla 1. Revisión de estudios sobre los genes implicados en la gravedad de la infección por SARS-CoV -2 .

\begin{tabular}{|c|c|c|c|c|c|c|}
\hline & $\begin{array}{l}\text { BASE DE } \\
\text { DATOS }\end{array}$ & AÑO & REVISTA & TÍTULO & AUTOR & PAÍS \\
\hline 1 & SciencieDirect & 2021 & $\begin{array}{l}\text { Medicina } \\
\text { Integral }\end{array}$ & $\begin{array}{l}\text { Estructura y función de las } \\
\text { citocinas }\end{array}$ & $\begin{array}{l}\text { X. Filellaa } \\
\text { et ál }\end{array}$ & España \\
\hline 2 & SCOPUS & 2020 & $\begin{array}{l}\text { Revista } \\
\text { Nature }\end{array}$ & $\begin{array}{l}\text { Elevated exhaustion levels } \\
\text { and reduced functional } \\
\text { diversity of } \mathrm{T} \text { cells in } \\
\text { peripheral blood may } \\
\text { predict severe progression } \\
\text { in COVID-19 patients }\end{array}$ & $\begin{array}{l}\text { Hong-Yi } \\
\text { Zheng et ál }\end{array}$ & China \\
\hline 3 & SciencieDirect & 2020 & $\begin{array}{l}\text { Medicina } \\
\text { Clínica }\end{array}$ & $\begin{array}{l}\text { Anti-IL-6 receptor } \\
\text { antibody treatment for } \\
\text { severe COVID-19 and the } \\
\text { potential implication of IL- } \\
6 \text { gene polymorphisms in } \\
\text { novel coronavirus } \\
\text { pneumonia }\end{array}$ & $\begin{array}{l}\text { Zulvikar } \\
\text { Syambani } \\
\text { Ulhaq et ál }\end{array}$ & Indonesia \\
\hline 4 & $\begin{array}{l}\text { Taylor \& } \\
\text { Francis }\end{array}$ & 2020 & $\begin{array}{l}\text { Emerging } \\
\text { Microbes \& } \\
\text { Infections }\end{array}$ & $\begin{array}{l}\text { Profiling serum cytokines } \\
\text { in COVID-19 patients } \\
\text { reveals IL- } 6 \text { and IL-10 are } \\
\text { disease severity predictors }\end{array}$ & $\begin{array}{l}\text { Huan Han } \\
\text { et ál }\end{array}$ & China \\
\hline 5 & PudMed & 2020 & $\begin{array}{l}\text { The Journal } \\
\text { of Clinical } \\
\text { Investigation }\end{array}$ & $\begin{array}{lrr}\text { Impaired immune } & \text { cell } \\
\text { cytotoxicity } & \text { in } & \text { severe } \\
\text { COVID-19 } & \text { is } & \text { IL-6 } \\
\text { dependent } & & \end{array}$ & $\begin{array}{l}\text { Alessio } \\
\text { Mazzoni et } \\
\text { ál }\end{array}$ & Italia \\
\hline 6 & Scielo & 2012 & $\begin{array}{l}\text { Revista } \\
\text { chilena de } \\
\text { cardiología }\end{array}$ & $\begin{array}{l}\text { Mayores niveles de ECA y } \\
\text { Angiotensina II } \\
\text { determinados } \\
\text { genéticamente, se asocian } \\
\text { a menor actividad del eje } \\
\text { ECA2/angiotensina-(1-9) } \\
\text { y mayor remodelamiento } \\
\text { de la pared aórtica de } \\
\text { ratas hipertensas. }\end{array}$ & $\begin{array}{l}\text { MOYA, } \\
\text { Jackeline } \\
\text { et al. }\end{array}$ & Chile \\
\hline
\end{tabular}




\begin{tabular}{|c|c|c|c|c|c|c|}
\hline & $\begin{array}{c}\text { BASE DE } \\
\text { DATOS }\end{array}$ & AÑo & REVISTA & TÍTULO & AUTOR & PAÍS \\
\hline 7 & $\begin{array}{l}\text { Springer } \\
\text { Nature }\end{array}$ & 2020 & $\begin{array}{l}\text { Nature } \\
\text { Biomedical } \\
\text { Engineering }\end{array}$ & $\begin{array}{l}\text { New insights into } \\
\text { genetic susceptibility of } \\
\text { COVID-19: an ACE2 and } \\
\text { TMPRSS2 } \\
\text { polymorphism analysis }\end{array}$ & $\begin{array}{l}\text { Yuan Hou } \\
\text { et ál }\end{array}$ & China \\
\hline 8 & SciencieDirect & 2019 & $\begin{array}{c}\text { European } \\
\text { Urology } \\
\text { Focus }\end{array}$ & 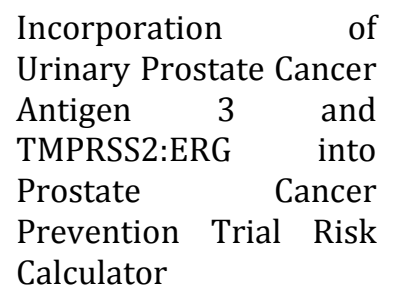 & $\begin{array}{l}\text { Donna } \\
\text { P.Ankerst } \\
\text { et ál }\end{array}$ & $\begin{array}{l}\text { Estados } \\
\text { Unidos }\end{array}$ \\
\hline 9 & Scopus & 2018 & Biomedica & $\begin{array}{l}\text { Classical HLA alleles tag } \\
\text { SNP in families from } \\
\text { Antioquia with type } 1 \\
\text { diabetes } \\
\text { mellitus][Polimorfismos } \\
\text { de un solo nucleótido } \\
\text { representativos para los } \\
\text { alelos clásicos del } \\
\text { antígeno leucocitario } \\
\text { humano en familias } \\
\text { antioqueñas con } \\
\text { diabetes mellitus tipo } 1\end{array}$ & $\begin{array}{l}\text { Sarrazola } \\
\text { et ál }\end{array}$ & Antioquia \\
\hline 10 & SciencieDirect & 2021 & $\begin{array}{l}\text { Medicina } \\
\text { Intensiva }\end{array}$ & $\begin{array}{lr}\text { HLA } & \text { genetic } \\
\text { polymorphisms and } \\
\text { prognosis of patients } \\
\text { with COVID-19 }\end{array}$ & $\begin{array}{l}\text { Lorente et } \\
\text { ál }\end{array}$ & España \\
\hline 11 & PudMed & 2015 & $\begin{array}{l}\text { The Journal } \\
\text { of Infection }\end{array}$ & $\begin{array}{l}\text { Functional } \\
\text { polymorphisms of the } \\
\text { CCL2 and MBL genes } \\
\text { cumulatively increase } \\
\text { susceptibility to severe } \\
\text { acute respiratory } \\
\text { syndrome coronavirus } \\
\text { infection }\end{array}$ & Tu et ál & China \\
\hline 12 & PudMed & 2020 & $\begin{array}{l}\text { Frontiers in } \\
\text { Genetics }\end{array}$ & $\begin{array}{l}\text { Host Genetic Variants } \\
\text { Potentially Associated } \\
\text { With SARS-CoV-2: A } \\
\text { Multi-Population } \\
\text { Analysis }\end{array}$ & Smatti et ál & Qatar \\
\hline 13 & Scopus & 2021 & $\begin{array}{l}\text { The Lancet } \\
\text { Healty } \\
\text { Longevity }\end{array}$ & $\begin{array}{l}\text { Androgenicity-not } \\
\text { serum testosterone- } \\
\text { correlates best with } \\
\text { COVID-19 outcome in } \\
\text { European males }\end{array}$ & $\begin{array}{l}\text { Giovanelli } \\
\text { et ál }\end{array}$ & Italia \\
\hline
\end{tabular}




\begin{tabular}{|c|c|c|c|c|c|c|}
\hline & $\begin{array}{l}\text { BASE DE } \\
\text { DATOS }\end{array}$ & AÑO & REVISTA & TÍTULO & AUTOR & PAÍS \\
\hline 14 & Scopus & 2021 & $\begin{array}{l}\text { The Lancet } \\
\text { Healty } \\
\text { Longevity }\end{array}$ & $\begin{array}{l}\text { Shorter androgen } \\
\text { receptor polyQ alleles } \\
\text { protect against life- } \\
\text { threatening COVID-19 } \\
\text { disease in European } \\
\text { males }\end{array}$ & $\begin{array}{l}\text { Baldassarri } \\
\text { et ál }\end{array}$ & Italia \\
\hline 15 & Scopus & 2020 & $\begin{array}{l}\text { European } \\
\text { Journal of } \\
\text { Preventive } \\
\text { Cardiology }\end{array}$ & $\begin{array}{l}\text { ABO blood group } \\
\text { predisposes to COVID- } \\
19 \text { severity and } \\
\text { cardiovascular diseases }\end{array}$ & Dai et ál & China \\
\hline 16 & SciencieDirect & 2020 & $\begin{array}{l}\text { Clínica } \\
\text { Chimica } \\
\text { Acta }\end{array}$ & $\begin{array}{lr}\text { Relationship between } \\
\text { ABO blood } & \text { group } \\
\text { distribution and clinical } \\
\text { characteristics in } \\
\text { patients with COVID-19 }\end{array}$ & Yuqin Wu & China \\
\hline
\end{tabular}

\section{Genes de inmunidad relacionados con la gravedad del covid 19}

\section{IL-6}

La IL-6 es una glucoproteína ubicada en el cromosoma 7 p15-21 es segregada por los "macrófagos, monocitos y células endoteliales" cuya función en intervenir en procesos virales cumpliendo un rol de defensa del organismo, ocasionando de esta manera efectos antiinflamatorios y proinflamatorios, las acciones del mismo están mediadas por dos subunidades R-IL6 y gp 130 (16).

Los estudios mencionan que el SARSCoV-2 invaden a las células $\mathrm{T}$, a su vez ocasiona que los macrófagos pulmonares produzcan citoquinas activando al TNF- $\alpha$ por lo que produce la muerte de las células $\mathrm{T}$, de esta manera los macrófagos producen IL-6 relacionándose con el "agotamiento de los linfocitos", por lo que la función proinflamatoria de la IL-6 ejecuta alteraciones en la "diferenciación de células $\mathrm{T}$ CD4+ $\mathrm{y}$ promueve el agotamiento de células $\mathrm{T}$ CD8+, disminuyendo la inmunidad antiviral del huésped" (17).

Zulvikar y colaboradores manifestaron que existe una correlación del alelo IL-6 174 con el SARS-CoV-2 ya que el alelo mencionado puede generar gravedad ante la COVID-19 pues el mismo ocasiona cuadros crónicos de neumonía (18).

Han, mencionó en su estudio que 102 pacientes con COVID-19 presentaron un estado crítico por los niveles altos de IL-6 (19). Así mismo, Mazzoni, reportó un análisis en 30 pacientes con niveles altos de IL-6 los mismos padecían de COVID-19 $\mathrm{y}$ presentaban condiciones de gravedad (20).

\section{ACE2 y TMPRSS2}

Los estudios han demostrado que las células diana para el ingreso y replicación del virus en los humanos son las células ACE2 "enzima convertidora de angiotensina II" y los TMPRSS2, estas proteínas de "membrana" se encuentran en los riñones, pulmones, corazón, testículos, vasos e intestino y células 
endoteliales, siendo importantes reguladores de la vasoconstricción y equilibrio de los electrolitos (21).

Yuan Hou analizó 81000 genomas de distintas "poblaciones"; especificó que la variaciones o polimorfismos del gen ACE2 y TMPRSS2, están directamente relacionados con la susceptibilidad y gravedad de COVID-19, demostrando que existieron 61 " variantes mortales del ACE2 " y 63 en el TMPRSS2, en ambos casos encontradas en la región codificante (22).

Así mismo el gen del TMPRSS2 al ubicarse en el cromosoma "21q22.3" su ARNm se expresa en las células epiteliales de la "próstata, senos, conducto biliar , riñón, colon, intestino delgado, páncreas, ovarios, glándulas salivales, estómago y pulmones", por lo que se menciona que los polimorfismos del gen pueden propiciar a una condición de gravedad en los pacientes con COVID-19 (23).

\section{HLA}

El virus del SARS-CoV-2 al incorporarse al organismo ocasiona una respuesta inmunitaria humoral y celular, promoviendo de esa manera la producción de anticuerpos dada por la respuesta del MHC "complejo principal de histocompatibilidad" el mismo "es una región genética conformada por genes" encargados de la inmunidad, además está ubicada en el brazo corto del cromosoma 6 también conocido como la región HLA, no obstante una de las principales funciones del mismo es distinguir entre las células propias del organismo y los cuerpos extraños que pueden ingresar (24) .

Las investigaciones han tratado de analizar sobre los posibles polimorfismos que pueden existir del HLA, por ello Xiaowei Li y colaboradores expresaron que hay alelos que presentan susceptibilidad ante el SARS-CoV-2 como "HLA-B $* 4601$,
HLA-B $*$ 0703, HLA-DR B1 $* 1202$ (47) y HLA-Cw $* 0801$, como también hay alelos de HLA-DR0301, HLA-Cw1502 y HLA-A * 0201" los cuales están asociados con la defensa ante una la infección por SARSCoV-2 (15) .

Lorente en su estudio ejecutado con 72 personas con COVID-19, manifestó que existía una relación entre los polimorfismos del HLA y el grado de susceptibilidad y mortalidad. Según los resultados del estudio los pacientes con COVID-19 presentaban los alelos HLA-B * 39 HLA-C * $16(\mathrm{p}=0,02)$ los mismos se manifiestan en algunas enfermedades infecciosas como el tuberculosis, no obstante también se demostró la presencia de los alelos HLA-A * 11, HLADQB1 * 04 y HLA-C * 01 desde luego estos alelos también se expresan en patologías más crónicas (25).

\section{CCL2 y $M B L$}

En el año 2015 un estudio realizado por Xinyi Tu y colaboradores expresaron la relación entre las quimiocinas con el grado de la susceptibilidad con el SARS, de hecho mencionaron que la baja producción y las variaciones funcionales del "CCL2 G-2518A y la variante del codón 54 de $M B L$ " contribuyen a la gravedad por SARS-CoV-1 (26).

Los genes CCL2 (cromosoma 17) y MBL (cromosoma 10), son quimiocinas, secretados por las células dendríticas, monocitos y macrófagos, las mismas ayudan a combatir infecciones virales (27).

No obstante estudios recientes manifestaron que las quimiocinas mencionadas están asociadas con el SARSCoV-2, de hecho Smatti y colaboradores a través de su investigación comunicaron que los polimorfismos de los genes CCL2 y MBL están relacionados con el nuevo 
coronavirus. Por ello ejecutaron una comparación entre los genomas de la población de Qatar y de Asia oriental, demostrando que el alelo de riesgo CCL5 (C, rs2280788) estaba con mayor frecuencia en la población de Asia oriental, mientras las variantes del MBL $(\mathrm{T}$, rs1800450) se presentaban en menor porcentaje en la población Africana. El estudio concluyó comunicando que las variantes de los genes pueden intervenir en la susceptibilidad y gravedad del SARSCoV-2 (27).

\section{Polimorfismos de genes asociados con la gravedad}

\section{polyQ del receptor de andrógenos}

El gen del receptor de andrógenos está ubicado en el cromosoma X justamente en el Xq11-q12, la misma expresa para una proteína la cual consta de tres dominios "el dominio de unión al DNA, modulatorio y unión hormonal" (28). Además posee un "tracto polyQ" en su extremo N-terminal, lugar donde puede expresar repeticiones de CAG (glutamina) y GGC lo cual puede generar polimorfismos, de hecho se menciona que las poblaciones de distintas nacionalidades presentan diferentes longitudes del polyQ (28).

Giovanelli manifestó que la "expansión y polimorfismos del tracto polyQ del receptor de andrógenos" coadyuva a los pacientes con COVID-19 a presentar una condición de gravedad (28) .

Baldassarri y colaboradores ejecutaron un estudio con 1178 personas de procedencia italiana y 117 (varones) de diferente origen europeo, explicaron que las repeticiones y polimorfismos del polyQ, conferían un estado de agresividad ante la infección por lo que en la investigación compararon el estado real del paciente, niveles séricos y de testosterona y dedujeron que los pacientes con gravedad poseían varias expansiones del polyQ. Concluyendo que mientras más corta es la expansión del polyQ los pacientes presentaban un menor riesgo de deterioro ante la infección provocada por el SARS CoV-2 (29) .

\section{Factor ABO}

En la actualidad investigaciones han comunicado la relación entre la susceptibilidad ante el virus y los tipos de sangre. De hecho Xiaofeng Dai, manifestó que las personas con grupo sanguíneo tipo $\mathrm{AB}$ presentan mayor complejidad ante la infección, así mismo menciona que los polimorfismos del gen ABO como "rs8176746, rs8176740, rs495828, rs12683493", estan relacionados con la funcionalidad de las $A C E 2$, provocando de esta manera que los pacientes con COVID19 padezcan de enfermedades cardiovasculares afectando el estado clínico de los mismos (30).

Yuqin Wu, ejecutó un análisis retrospectivo en 187 pacientes con COVID19 con el objetivo verificar la frecuencia de los grupos sanguíneos y las condiciones clínicas de los participantes, en su investigación concluyó que el $36.90 \%$ de los participantes poseían el grupo sanguíneo tipo A en comparación al grupo control $(36,90 \%$ vs. $27,47 \%, \mathrm{P}=0,006)$, el $33.69 \%$ el grupo sanguíneo tipo B, el $21.92 \%$ tipo $\mathrm{O}(21,92 \%$ frente a $30,19 \%, \mathrm{P}$ $=0,018$ ) y el $7,49 \%$ tipo $\mathrm{AB}$, por lo que dedujo que los participantes con el tipo de sangre A presentaron un mayor riesgo de infectividad en comparación de los demás (31).

\section{Discusión}

Aun no hay certeza sobre el verdadero comportamiento del virus en la población ya que ha desencadenado múltiples 
consecuencias en las personas. Sin embargo, los genes pueden determinar la repuesta del organismo ante la exposición del virus, algunos de ellos están directamente relacionados con los mecanismos de acción del SARS-CoV-2.

Zulvikar y Gita establecen que el portador del alelo IL-6-174 desempeña un papel importante en la progresión de la neumonía por SARS-CoV-2, puesto que el tratamiento de inhibición de la producción de la IL-6 permite determinar una terapia adecuada para el tratamiento del síndrome de dificultad respiratoria aguda (32). Sin embargo, la información descrita no permite establecer una relación directa de un polimorfismo del gen IL-6 con la gravedad de la infección por SARS-CoV-2.

De la misma manera, los estudios mencionan que las ACE2 y TMPRSS2 son los receptores de ingreso y expansión del SARS-CoV-2. De hecho Xin Zou y colaboradores manifiestan que la expresión de las ACE2 se produce en varios órganos por ello explican que algunos pacientes con COVID-19 padecen de síntomas multisistémicos. De la misma manera contribuyen a que la subexpresión de las ACE2 conllevan a una condición de susceptibilidad a la infección por SARS-CoV-2 (33). Mientras Yuan Hou atribuye que la población que presentan polimorfismos en estos genes padecen de cuadros de gravedad ante la COVID-19 (22).

Los polimorfismos del HLA han permitido determinar que existe una gran relación con la gravedad de la COVID-19. Diferentes estudios como el de Lorente han presentado la existencia de genes que producen susceptibilidad en las personas que contraen la infección, esto se debe a que ciertos polimorfismos del HLA en ocasiones causan una deficiencia en la acción inmunitaria (25). En cambio
Xiaowei Li menciona que también existen polimorfismos del HLA que generan protección ante la infección (15).

Xinyi Tu y colaboradores asociaron la baja producción de CCL2 y MBL con la gravedad ante la infección por SARS-CoV1. En cambio en el año 2020 se vuelve a mencionar los mismos genes con relación al SARS -CoV-2, pues se determinó que las variantes de los genes CCL2 y MBL están involucradas con la susceptibilidad y gravedad ante la COVID-19 (27).

Así mismo las investigaciones expresan que los polimorfismos del polyQ del receptor de andrógenos y factor $\mathrm{ABO}$, conllevan a que las poblaciones presenten cuadros de gravedad ante la infección provocada por el SARS -CoV-2. De hecho, Xiaofeng Dai menciona que los polimorfismos en el factor $\mathrm{ABO}$ desencadena una serie de afecciones ya que esa relacionado con las ACE2 intensificando de esa manera una condición de gravedad. Sin embargo Rebecca $\mathrm{K}$ demostró en su estudio ejecutado con 2033 pacientes con COVID19 en estado grave; que no hubo relación entre la tasa de mortalidad y los fenotipos ABO (34).

\section{CONCLUSIONES}

$\mathrm{L}$ os estudios demostraron que existen genes involucrados en la gravedad ante la infección de SARS CoV-2, pues mencionan que algunos polimorfismos de los genes; HLA, del polyQ del receptor de andrógenos y factor $\mathrm{ABO}$ producen susceptibilidad, influyendo sobre la condición fisiológica y fisiopatológica de los pacientes. Así mismo los genes ACE2 y TMPRSS2 intervienen en el ingreso y expansión del virus.

Desde luego en las diversas razas existen variantes de los genes CCL2 y MBL 
lo que indica que algunas poblaciones son más susceptibles ante otras, por ello que se puede explicar la gravedad que padecen las personas ante la COVID-19.

\section{REFERENCIAS BIBLIOGRÁFICAS}

1. Ena J, Wenzel RP. Un nuevo coronavirus emerge. Rev Clin Esp. 2020;220(2):115-6. Disponible en: https://www.ncbi.nlm.nih.gov/pmc/articles /PMC7130265/.

2. Buendía CM, López FM. Ecografía pulmonar en enfermos con coronavirus COVID-19: Revista del Hospital "Dr Emilio Ferreyra". 2020;1(1):e22-4. Disponible en: http://revista.deiferreyra.com/index.php/R HEF/article/view/18.

3. Ruíz ÁL, Molina R. Tromboembolismo pulmonar masivo paciente neumonía COVID-19 positivo.Revista Chilena de Anestesia. 2019; 49. Disponible en: https://revistachilenadeanestesia.cl/revchil anestv49n03-023/.

4. Chan JF-W, Yuan S, Kok K-H, To KK-W, Chu $\mathrm{H}$, Yang J, et al. A familial cluster of pneumonia associated with the 2019 novel coronavirus indicating person-to-person transmission: a study of a family cluster. The Lancet, 395(10223):514-23. Disponible en: https://www.thelancet.com/journals/lancet /article/PIIS0140-6736(20)30154-

9/abstract.

5. Lu R, Zhao X, Li J, Niu P, Yang B, Wu H, et al. Genomic characterisation and epidemiology of 2019 novel coronavirus: implications for virus origins and receptor binding. The Lancet; 395(10224):565-74. Disponible en: https://www.thelancet.com/journals/lancet /article/PIIS0140-6736(20)30251-

8/abstract.

6. Ramiro-Mendoza MS. Epidemiología del SARS-CoV-2. Acta Pediatra. 2020;41(S1):8$14 . \quad$ Disponible en: https://www.medigraphic.com/cgibin/new/resumen.cgi?IDARTICULO=94498.
7. OMS. COVID-19: cronología de la actuación de la OMS. 2020. Disponible en: https://www.who.int/es/news-

room/detail/27-04-2020-who-timeline--covid-19.

8. Johns Hopkins Coronavirus Resource Center. COVID-19 Map [Internet]. Johns Hopkins Coronavirus Resource Center. 2020. Disponible en: https://coronavirus.jhu.edu/map.html.

9. Wang D, Hu B, Hu C, Zhu F, Liu X, Zhang J, et al. Clinical Characteristics of 138 Hospitalized Patients With 2019 Novel Coronavirus-Infected Pneumonia in Wuhan, China. JAMA. 2020;323(11):1061-9. Disponible en: https://jamanetwork.com/journals/jama/fu llarticle/2761044.

10. Huang $X$, Wei F, Hu L, Wen L, Chen K. Epidemiology and Clinical Characteristics of COVID-19. Arch Iran Med. 01 de 2020;23(4):268-71. Disponible en: 10.34172/aim.2020.09.

11. Debnath $M$, Banerjee $M$, Berk $M$. Genetic gateways to COVID-19 infection: Implications for risk, severity, and outcomes. The FASEB Journal. 2020;34(7):8787-95. Disponible en: https://faseb.onlinelibrary.wiley.com/doi/a bs/10.1096/fj.202001115R.

12. Renieri A, Benetti $E$, Tita R, Spiga $O$, Ciolfi A, Birolo $G$, et al. ACE2 variants underlie interindividual variability and susceptibility to COVID-19 in Italian population. medRxiv. 2020.04.03.20047977. Disponible en: https://www.medrxiv.org/content/10.1101 /2020.04.03.20047977v1.

13. Asselta R, Paraboschi EM, Mantovani A, Duga S. ACE2 y TMPRSS2 Variantes y expresión como candidatos a las diferencias de sexo y país en la gravedad de COVID-19 en Italia. Science Research Network; 2020; Disponible en: https://papers.ssrn.com/abstract=3559608.

14. Goldstein MR, Poland GA, Graeber CW. Does apolipoprotein E genotype predict COVID-19 severity? QJM. 2020; Disponible en: https://www.ncbi.nlm.nih.gov/pmc/ articles/PMC7197574/. 
15. Li X, Geng M, Peng Y, Meng L, Lu S. Molecular immune pathogenesis and diagnosis of COVID-19. Journal of Pharmaceutical Analysis. 2020 10(2):102-8. Disponible en: http://www.sciencedirect.com/science/arti cle/pii/S2095177920302045.

16. Filella $\mathrm{X}$, Molina $\mathrm{R}$, Ballesta AM. Estructura y función de las citocinas. Med Integr 2002; 39(2):63-71. Disponible en: http://www.elsevier.es/es-revistamedicina-integral-63-articulo-estructurafuncion-citocinas-13026682.

17. Zheng H-Y, Zhang $M$, Yang C-X, Zhang $\mathrm{N}$, Wang $\mathrm{X}-\mathrm{C}$, Yang $\mathrm{X}-\mathrm{P}$, et al. Elevated exhaustion levels and reduced functional diversity of $\mathrm{T}$ cells in peripheral blood may predict severe progression in COVID-19 patients. Cellular \& Molecular Immunolog. 2020;17(5):541-3. Disponible en: https://www.nature.com/articles/s41423020-0401-3.

18. Ulhaq ZS, Soraya GV. Anti-IL-6 receptor antibody treatment for severe COVID-19 and the potential implication of IL-6 gene polymorphisms in novel coronavirus pneumonia. Medicina Clínica. 2020;155(12):548-56. Disponible en: https://www.sciencedirect.com/science/art icle/pii/S0025775320304498.

19. Han H, Ma Q, Li C, Liu R, Zhao L, Wang $\mathrm{W}$, et al. Profiling serum cytokines in COVID19 patients reveals IL-6 and IL-10 are disease severity predictors. Emerging Microbes \& Infections. 2020;9(1):1123-30. Disponible

en: https://doi.org/10.1080/22221751.2020.17 70129.

20. Mazzoni A, Salvati L, Maggi L, Capone M, Vanni A, Spinicci $M$, et al. Impaired immune cell cytotoxicity in severe COVID-19 is IL-6 dependent. J Clin Invest. 2020;130(9):4694-703. Disponible en: https://www.jci.org/articles/view/138554.

21. Moya J, Novoa U, Escudero N, Godoy I, Chiong M, Lavandero S, et al. Mayores niveles de ECA y Angiotensina II determinados genéticamente, se asocian a menor actividad del eje ECA2/angiotensina(1-9) y mayor remodelamiento de la pared aórtica de ratas hipertensas. Revista chilena de cardiología. 2012;31(2):118-28. Disponible en: https://scielo.conicyt.cl/scielo.php?script=sc i_abstract\&pid=S0718-

$85602012000200006 \& \operatorname{lng}=e s \& n r m=i s o \&$ th $\mathrm{g}=\mathrm{es}$.

22. Hou Y, Zhao J, Martin W, Kallianpur A, Chung MK, Jehi L, et al. New insights into genetic susceptibility of COVID-19: an ACE2 and TMPRSS2 polymorphism analysis. BMC Medicine. 2020;18(1):216. Disponible en: https://doi.org/10.1186/s12916-02001673-z.

23. Ankerst DP, Goros M, Tomlins SA, Patil D, Feng Z, Wei JT, et al. Incorporation of Urinary Prostate Cancer Antigen 3 and TMPRSS2:ERG into Prostate Cancer Prevention Trial Risk Calculator. European Urology Focus. 2019;5(1):54-61. Disponible en:

http://www.sciencedirect.com/science/arti cle/pii/S2405456918300117.

24. Sarrazola DC, Rodríguez AM, Toro $M$, Vélez A, García-Ramírez J, Lopera MV, et al. Classical HLA alleles tag SNP in families from Antioquia with type 1 diabetes mellitus. Biomedica. 2018;38(3):329-37.

25. Lorente L, Martín MM, Franco A, Barrios Y, Cáceres JJ, Solé-Violán J, et al. HLA genetic polymorphisms and prognosis of patients with COVID-19. Medicina Intensiva. 2021;45(2):96-103. Disponible en: https://www.sciencedirect.com/science/art icle/pii/S0210569120302667

26. Tu X, Chong WP, Zhai $\mathrm{Y}$, Zhang $\mathrm{H}$, Zhang $F$, Wang $S$, et al. Functional polymorphisms of the CCL2 and MBL genes cumulatively increase susceptibility to severe acute respiratory syndrome coronavirus infection. Pumed. 2015;71(1):101-9. Disponible en: 10.1016/j.jinf.2015.03.006

27. Smatti MK, Al-Sarraj YA, Albagha O, Yassine HM. Host Genetic Variants Potentially Associated With SARS-CoV-2: A Multi-Population Analysis. Front Genet. 2020;11:578523. Disponible en: 10.3389/fgene.2020.578523. 
28. Giovanelli L, Quinton R. Androgenicity-not serum testosteronecorrelates best with COVID-19 outcome in European males. EBioMedicine. 2021;66. Disponible en: https://www.thelancet.com/journals/ebiom /article/PIIS2352-3964(21)00079-

7/abstract.

29. Baldassarri M, Picchiotti N, Fava F, Fallerini C, Benetti E, Daga S, et al. Shorter androgen receptor polyQ alleles protect against life-threatening COVID-19 disease in European males. EBioMedicine .2021; 65 . Disponible en: https://www.thelancet.com/journals/ebiom /article/PIIS2352-3964(21)00039-

6/abstract.

30. Dai X. ABO blood group predisposes to COVID-19 severity and cardiovascular diseases. European Journal of Preventive Cardiology 2020 ;27(13):1436-7. Disponible en:

https://doi.org/10.1177/20474873209223 70.

31. Wu Y, Feng Z, Li P, Yu Q. Relationship between $\mathrm{ABO}$ blood group distribution and clinical characteristics in patients with COVID-19. Clinica Chimica Acta. 2020; 509:220-3. Disponible en: https://www.sciencedirect.com/science/art icle/pii/S0009898120302904.
32. Serrano García A, Montánchez Mateo J, Franch Pato CM, Gómez Martínez R, García Vázquez P, González Rodríguez I. Relación entre los niveles de interleucina 6 y depresión en pacientes afectados por Covid19. Med Clin (Barc) 2021. Disponible en: https://www.ncbi.nlm.nih.gov/pmc/articles /PMC7837017/

33. Zou X, Chen K, Zou J, Han P, Hao J, Han Z. Single-cell RNA-seq data analysis on the receptor ACE2 expression reveals the potential risk of different human organs vulnerable to 2019-nCoV infection. Frontiers of Medicine. 2020;14. Disponible en: https://doi.org/10.1007/s11684-020-07540

34. Leaf RK, Al-Samkari H, Brenner SK, Gupta S, Leaf DE. ABO phenotype and death in critically ill patients with COVID-19. British Journal of Haematology. 2020;190(4):e204-8. Disponible en: https://onlinelibrary.wiley.com/doi/abs/10. 1111/bjh.16984

Conflicto de interese: Los autores declaran que no existe conflicto de intereses para la publicación del presente artículo.

Financiamiento: Autofinanciamiento

Agradecimiento: No declaran 